\title{
Past price "memory" in the housing market: testing the performance of different spatio-temporal specifications.
}

DOI:

10.1080/17421772.2018.1395063

\section{Document Version}

Accepted author manuscript

Link to publication record in Manchester Research Explorer

\section{Citation for published version (APA):}

Dubé, J., Legros, D., \& Thanos, S. (2018). Past price "memory" in the housing market: testing the performance of different spatio-temporal specifications. Spatial Economic Analysis, 13(1), 118-138.

https://doi.org/10.1080/17421772.2018.1395063

\section{Published in:}

Spatial Economic Analysis

\section{Citing this paper}

Please note that where the full-text provided on Manchester Research Explorer is the Author Accepted Manuscript or Proof version this may differ from the final Published version. If citing, it is advised that you check and use the publisher's definitive version.

\section{General rights}

Copyright and moral rights for the publications made accessible in the Research Explorer are retained by the authors and/or other copyright owners and it is a condition of accessing publications that users recognise and abide by the legal requirements associated with these rights.

\section{Takedown policy}

If you believe that this document breaches copyright please refer to the University of Manchester's Takedown Procedures [http://man.ac.uk/04Y6Bo] or contact uml.scholarlycommunications@manchester.ac.uk providing relevant details, so we can investigate your claim.

\section{OPEN ACCESS}




\title{
Past price "memory" in the housing market: testing the performance of different spatio-temporal specifications.
}

\author{
Jean Dubé \\ Centre de Recherche en Aménagement et Développement, Laval University \\ Corresponding author: email: Jean.Dube@ esad.ulaval.ca, tel : 418-656-2131 \#6763 \\ Diègo Legros \\ Laboratoire d'Économie et de Gestion, Université de Bourgogne \\ Sotirios Thanos \\ School of Environment, Education \& Development, University of Manchester
}

\begin{abstract}
Recent methodological developments provide a way to incorporate the temporal dimension, when accounting for spatial effects in hedonic pricing. Weight matrices should decompose the spatial effects into two distinct components: i) bidirectional contemporaneous spatial connections; ii) and unidirectional spatio-temporal effects from past transactions. Our iterative estimation approach explicitly analyses the role of time in price determination. The results show that: both spatio-temporal components should be included in model specification; past transaction information stops contributing to price determination after 8 months; limited temporal friction is exhibited within this period. These findings highlight the decidedly non-linear temporal patterns of such information effects.
\end{abstract}

KEY WORDS: Hedonic pricing; Spatial econometrics; Spatial weight matrix; Spatiotemporal; Housing market; STAR; SAR

JEL Codes: C21; C40; R10; R15

This is an Accepted Manuscript of an article published by Taylor \& Francis Group in Spatial Economic Analysis on 06/10/2017. Please cite as:

Dubé, J., Legros, D., Thanos, S. (2018), Past price "memory" in the housing market: testing the performance of different spatio-temporal specifications. Spatial Economic Analysis, 13, 118-138 http://dx.doi.org/10.1080/17421772.2018.1395063 


\section{Introduction}

The role of the spatial dimension in the house price determination process has been widely recognized for a while now (Can, 1992), whereas the role of the temporal dimension has been typically restricted in part of the literature to price indices (Case and Shiller, 1989, 1987; Case et al., 1992; Clapp and Giacotto, 1992). According to recent real estate literature (Dubé and Legros, 2013a, 2014a; Nase et al., 2016; Thanos et al., 2016) using hedonic pricing (HP) models, the spatial connections can be decomposed to account for the data not being strictly spatial, but rather spatio-temporal in nature. Arrow of time violations can occur, when the spatial aspect of the data is modelled and the temporal aspect is ignored (Dubé and Legros, 2013a, 2014a; Nase et al., 2016; Thanos et al., 2016). It is also stressed that real estate transaction data are not spatial panel data, as individual observations occur in a specific place at a particular time and are treated as being strictly independent (Thanos et al., 2016).

The temporal dimension of real estate transaction data allows the introduction of what professional real estate agents typically refer to as the "comparable sales" approach (Isakson, 2002; Des Rosiers et al., 2011; Thanos et al., 2016). Modelling such effects exhibits methodological challenges, since the "comparable sales" effect involves transactions occurring in the past and thus the temporal dimension must necessarily be taken into account.

In fact, the temporal dimension introduces constraints on the spatial connections. The most common approach that expresses these temporal constraints on spatial relations is based on a lower-triangular specification of the weight matrix $\mathbf{W}^{1}$ (Can and Megbolugbe, 1997; Pace et al., 1998). However, this representation is quite restrictive, as it does not allow the introduction of spatial bidirectional "spillover" relation, which is one of the main features of spatial econometrics (Elhorst, 2014; LeSage and Pace, 2009). Moreover, the strictly lower triangular specification of the weight matrix assumes that there is no

\footnotetext{
1 In spatial econometrics, the $\mathbf{W}$ matrix defines the spatial interactions between observations. It is exogenously defined and usually based on Euclidean distance.
} 
time decay in the spatial information. ${ }^{2}$ The consideration of the bidirectional spatial relations is possible when the spatial weight matrix is based on a block-diagonal decomposition (Dubé and Legros, 2013b). In this case, a "peer effect" is assumed to occur within the same time period or a pre-defined time window, and the decomposition of the marginal effect into the direct and total effects is possible (LeSage and Pace, 2009). Hence, spatial effects for real estate transaction data can be split into two distinct components (Thanos et al., 2016): i) a bidirectional contemporaneous spatial "peer effect" (i.e. the typical spatial autoregressive effect) and ii) a unidirectional spatiotemporal past price effect (i.e. the comparable sales effect). However, there little empirical evidence in the literature on how the relationships in these components should be specified.

This paper provides empirical evidence on the performance of different spatio-temporal specifications, developing the research of Dubé and Legros (2013a; 2014a) and Thanos et al., (2016) across the following novel, but highly interrelated, aspects: i) The performance of the spatio-temporal model, accounting for both bidirectional (peer) and unidirectional (comparable) spatial connections, is tested against the typical spatial specification and the lower triangular matrix specification. ii) An approach of simultaneously determining the optimal temporal distance friction parameter and the critical temporal cut-off point (horizon) is specified. This specification of the temporal friction and cut-off point is further validated by out-of-sample estimation. iii) The difference between the strictly spatial (misspecified) and the spatio-temporal approach is examined by looking at the correlation between the different matrices. This tests whether temporal restrictions to spatial connections can address LeSage's and Pace's (2014) "biggest myth in spatial econometrics", concerning spatio-temporal data contexts.

The rest of the paper is structured into the following sections. The second section discusses the theoretical principles and the resulting methodological approach. The third section illustrates the empirical strategies for building appropriate weight matrices, and

\footnotetext{
${ }^{2}$ Of course, this situation can be relaxed by introducing some additional information regarding the
} temporal distance (see section 3.1 below). 
data used for the analysis. The fourth section presents the empirical results of applying the models to data from Aberdeen, Scotland. The fifth section of the paper draws conclusions and identifies the current and future challenges related to modelling real estate transaction data.

\section{Revisiting Spatial and Spatio-temporal HP Models}

\subsection{Theoretical framework}

In the hedonic pricing (HP) method (Rosen, 1974), the price yit of house $i$ sold at time $t$, is expressed as a function of its characteristics, xikt, in equation 1. Assuming that the relation is linear in parameters, the estimated coefficients, $\beta_{k}$, express the implicit price of each of the $\mathrm{k}=1,2, \ldots, \mathrm{K}$ amenities. The time dummy variables are represented by $D_{i t}$,

and their parameters, $\delta_{t}$, control for the nominal evolution of the prices and capture temporal heterogeneity (Wooldridge, 2001).

$$
y_{i t}=\alpha+\sum_{k=1}^{K} \beta_{k} x_{i k t}+\sum_{t=1}^{T-1} \delta_{t} D_{i t}+\varepsilon_{i t}
$$

Kuminoff and Jarrah (2010) contend that if spatially delineated attributes are conveyed through the location of a house, it seems reasonable to assume that each house is perceived as unique by consumers. Following Thanos et al. (2016), this framework is extended to include the temporal dimension. House prices $y_{i t}$ are time-variant due to constant shifts in market conditions and household preferences. Each house price is reached by local equilibria between supply and demand for the housing attribute bundles at the specific time $t$ and location $i$. The hedonic price of each house can only analysed through the available information to buyers up to the time of the sale. The buyer is influenced by other sales in temporal and spatial proximity that provide information on how non-identical bundles of housing attributes are capitalised in the market. 
We provide here a detailed description of the a priori expectations for the data generating process (DGP) in this paper. Apart from the information on all observable attributes $x_{i k t}$ of house $i$ at time $t$, the buyer:

a) may interact and compete with other buyers and sellers directly or through agents within the very limited time period typically contingent to market specific sale procedures and mechanisms. These interactions are not observed by the researcher, but the resulting house prices are. Hence, the price $y_{h t}$ of spatial neighbour $h$ serves as a proxy for this interaction. By definition, this contemporaneous effect exists as long as the final prices are not observed by the competing buyers (see below for the alternative case). This is a short-term endogenous effect that has a strong pecuniary aspect, but can also capture short term reactions to technological shocks, if these are prominent in the data.

b) has also access to information on the past sale price $y_{j(t-\theta)}$ of house $j$ in time $t-\theta$. The effects from a past sale $y_{j(t-\theta)}$ are unidirectional and can include pecuniary and technological spillovers. Explaining further the comparable past sales paradigm, the market participants treat past sale prices as information sources for the equilibrium between housing supply and demand that changes across time and space. This denotes that market participants seek sale prices, as proximal in time and space as possible, to minimise information decay. $\theta$ is the cut-off point of how far in the past market participants will look for information. Information from sales not proximal is discounted accordingly to spatio-temporal distance until there is no effect from that information (Thanos et al., 2016).

As illustrated in the discussion above, these effects are specified as autoregressive terms, suggesting $^{3}$ the spatio-temporal autoregressive (STAR) model form presented in Equation 2:

$$
y_{i t}=\alpha+\psi \sum_{j=1}^{J} w_{i j} y_{j(t-\theta)}+\rho \sum_{h=1}^{H} w_{i h} y_{h t}+\sum_{k=1}^{K} \beta_{k} x_{i k t}+\sum_{t=2}^{T} \delta_{t} D_{i t}+\varepsilon_{i t}
$$

\footnotetext{
${ }^{3}$ A HP spatio-temporal error model (STEM) may be relevant when data is mostly comprised of new-build houses or extensive house improvements, as in Thanos et al., (2015). This is not the case with our data.
} 
where the parameters $\psi$ and $\rho$ represent the "comparable sales" and "contemporaneous peer" effects respectively. Time and space have different measurement units. Therefore, temporal distance is treated as a time decay function that multiplies a function of the spatial distance. The spatio-temporal distance $w_{i j}$ between observations $i$ and $j$ is given by the product of the function spatial distance $d_{i j}$ multiplied by a function of the temporal distance $\tau_{i j}\left[\mathrm{w}_{\mathrm{ij}}=f\left(d_{i j}\right) \times f\left(\tau_{i j}\right)\right]$. This suggests a Hadamard product is the appropriate way of combining spatial and temporal distance matrices in a single spatio-temporal matrix (Thanos et al., 2016; Dubé and Legros, 2013a).

Spatial econometrics HP models typically rely on the "exogenous" specification of the weight matrix, $\mathbf{W}$, which is not without challenge. These challenges focus on the overconnectivity problem (Smith, 2009), the unit roots problem of the spatial autoregressive coefficient (Dubé and Legros, 2013a; 2013b), the imprecision of the out-of-sample performance (Dubé and Legros, 2014b), and the challenge of identifying an appropriate data generating processes that is not subject to the endogeneity criticism (Gibbons and Overman, 2012; Gibbons et al., 2014). Furthermore, LeSage and Pace (2014) argue that changing the a priori specified number of spatial relations expressed in matrix $\mathbf{W}$ does not necessarily lead to changes in the model results, as the correlation between the different spatial matrix specifications is very high. The STAR HP framework introduced in this section provides the premise for empirical tests on the performance of different STAR specifications below that partly address these challenges.

\subsection{The spatial and spatio-temporal HP models}

This section provides the different models that represent the constrained versions of STAR we are testing for, after we briefly discuss spatial autoregressive (SAR) model. The SAR specification of the HP model in equation 3 assumes that prices are interdependent with neighbouring house prices, as captured through the term $\mathbf{W y}$. In matrix notation, the dependent variable, usually the logarithmic transformation of the sale price, is stacked in a vector $\mathbf{y}$ of dimension $\left(\mathrm{N}_{\Gamma} \times 1\right)$. The matrix of covariates, denoted by $\mathbf{X}$, is of dimension $\left(\mathrm{N}_{\Gamma} \times \mathrm{K}\right)$ and time dummy variables are stacked in matrix $\mathbf{D}$ of 
dimension $\left[\mathrm{N}_{\Gamma} \times(\mathrm{T}-1)\right]$, where $\Gamma$ is the total number of time periods $(t=1,2, \ldots, T)$, and $\mathrm{N}_{\Gamma}$ is the total number of observations $\left(N_{\Gamma}=\sum_{t=1}^{T} N_{t}\right){ }^{4}$ In strictly spatial representations, $\mathbf{W}$ is typically, but not necessarily, a symmetric weight matrix expressing only the spatial relations between the individual observations.

$$
\mathbf{y}=\rho \mathbf{W y}+\mathbf{\imath} \alpha+\mathbf{D} \boldsymbol{\delta}+\mathbf{X} \boldsymbol{\beta}+\boldsymbol{\varepsilon}
$$

The vectors of parameters, $\boldsymbol{\delta}$ and $\boldsymbol{\beta}$, are, respectively, of dimension $[(\mathrm{T}-1) \times 1]$ and $(\mathrm{K} \times$ 1 ), while $\alpha$ is a scalar, vector $\mathbf{t}$ is composed of elements equal to 1 and is of dimension $\left(\mathrm{N}_{T} \times 1\right)$. The vector of error terms, $\boldsymbol{\varepsilon}$, is also of dimension $\left(\mathrm{N}_{\Gamma} \times 1\right)$. This specification has been quite popular allowing for the estimation of spatial spillover effect (LeSage, 2014; Elhorst, 2014; LeSage and Pace, 2009). However, this representation holds only for purely cross-sectional data, which is not the case for disaggregate real estate transaction data.

As already discussed, $\mathbf{W}$ must be constrained according to the temporal relations (Thanos et al., 2012, 2015; Dubé and Legros, 2013b; Dubé et al., 2013; 2014; Huang et al., 2010; Smith and $\mathrm{Wu}, 2009$; Nase et al., 2016). One way to ensure that the spatial connections capture only the effects from previous observations is to adopt a lower triangular weight matrix, noted $\underline{\mathbf{W}}$. The use of this matrix transforms the model to a unidirectional spatiotemporal autoregressive (STAR-U) model in equation 4.

$$
\mathbf{y}=\psi \underline{\mathbf{W y}}+\mathbf{\imath} \alpha+\mathbf{D} \boldsymbol{\delta}+\mathbf{X} \boldsymbol{\beta}+\boldsymbol{\varepsilon}
$$

In this case, the autoregressive coefficient, $\psi$, captures the effect of past observations on current observations or the unidirectional comparable sales effect. The distinction between indirect and direct marginal effect is not possible here (LeSage and Pace, 2009). The advantage of such specification is that the model can be estimated by ordinary least squares (OLS) or generalized least squares (GLS) (Pace et al., 1998; Can and

\footnotetext{
${ }^{4}$ This is where it is explicit that dealing with spatial data pooled over time is different from the spatial panel case, where the total number of observations is given by NT when the panel is balanced.
} 
Megbolugbe, 1997). This is because the variable $\underline{\mathbf{W}} \mathbf{y}$ is information from previous time periods $(t-\theta)$ and hence strictly exogenous from the perspective of economic agents (buyers and sellers) in the current time period $(t)$. The strictly lower-triangular specification, without any temporal friction (decay) and temporal horizon (cut-off point), may not fully account for the temporal distance between the observations. The specification in equation 4 precludes the contemporaneous bidirectional spatial relations from the model.

Isolating the contemporaneous spatial connections is possible by taking the block diagonal matrix, $\mathbf{S}$, expressing spatial relations between observations collected in the same time period. The block decomposition is based on distinct $\mathbf{S}_{\mathbf{t t}}$ matrices synthetizing the spatial relations between observations collected in the same time period $t$. The coefficient $\rho$ captures the spatial autoregressive effect within the same period, not across observations from all time periods, as in SAR. Given that the relations in matrix $\mathbf{S}$ are much sparser than matrix $\mathbf{W}$ in equation 3 , the correlation between the two matrices should be low. The model is denoted as the bidirectional spatio-temporal autoregressive (STAR-B) model in equation 5.

$$
\mathbf{y}=\rho \mathbf{S y}+\mathbf{\imath} \alpha+\mathbf{D} \boldsymbol{\delta}+\mathbf{X} \boldsymbol{\beta}+\boldsymbol{\varepsilon}
$$

An advantage of such specification is that the calculation of the (direct, indirect and total) marginal effects can be obtained using the weight matrix and the estimated value of the parameter $\rho$ (LeSage, 2014).

Equation 6 provides in matrix notation the STAR model of equation 3 that includes both $\underline{\text { Wy }}$ and Sy.

$$
\mathbf{y}=\rho \mathbf{S y}+\psi \underline{\mathbf{W}} \mathbf{y}+\mathbf{l} \alpha+\mathbf{D} \boldsymbol{\delta}+\mathbf{X} \boldsymbol{\beta}+\boldsymbol{\varepsilon}
$$

This specification estimates both $\rho$ and $\psi$, the bidirectional and unidirectional effects respectively. Here, the direct, indirect and total marginal effects could be calculated using 
the $\rho$, while the $\psi$ coefficient can be used to evaluate short and long-run marginal effects, as in the STAR-U model (Dubé et al., 2017).

Figure 1 illustrates the relationships between the different model types according to different restrictions on the coefficients. The identification of the better specification can easily be conducted using a likelihood ratio (LR) test using the constrained and unconstrained version of the model. It is noted that there exists no explicit link between these specifications and the typical SAR (equation 3), in which the full spatial weight matrix, W, does not include temporal relations. Moreover, there is no formal relation between the STAR-B and STAR-U model. Thus, it is conceptually impossible to compare the results obtained using the typical spatial econometric specification (SAR) to results obtained using the spatio-temporal econometric specifications (STAR, STAR-U, and STAR-B).

Figure 1: Links between the spatio-temporal models specifications

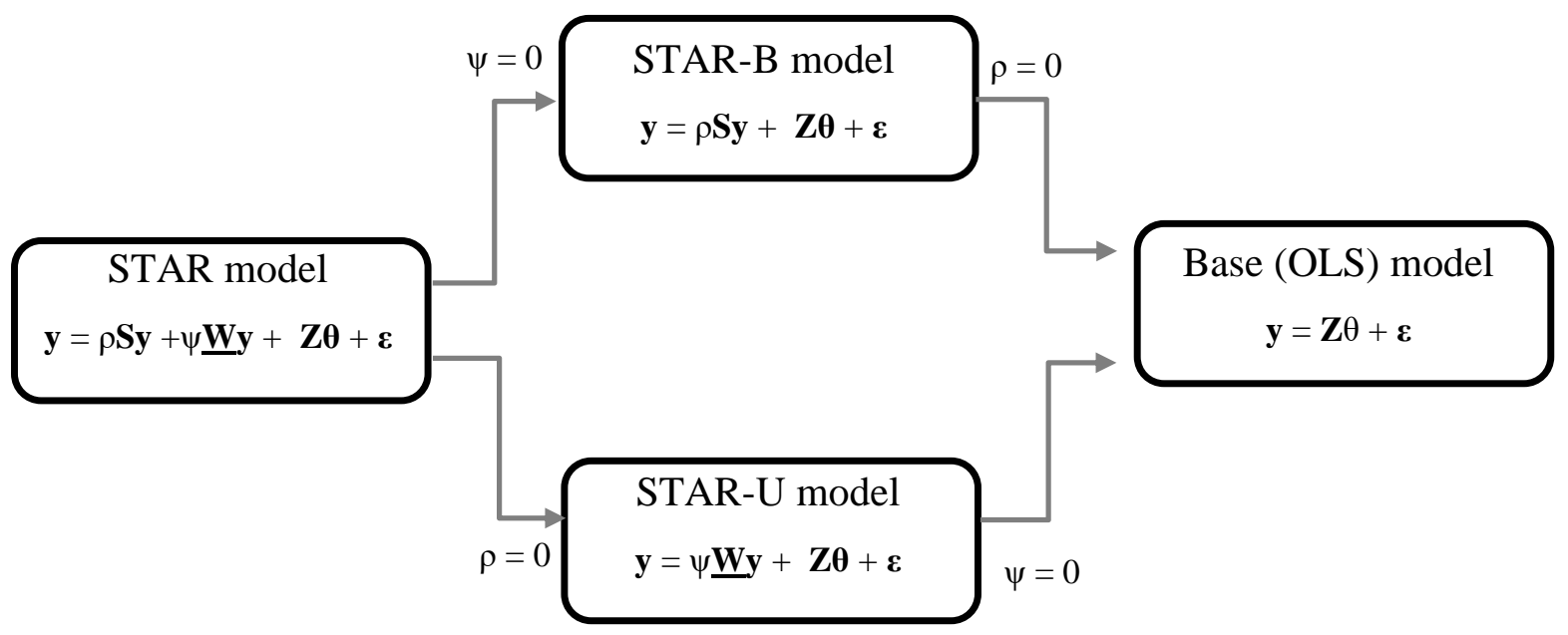

Note: $\mathbf{Z} \theta=\mathbf{\imath} \alpha+\mathbf{D} \boldsymbol{\delta}+\mathbf{X} \boldsymbol{\beta}$; STAR-B (spatio-temporal autoregressive model with bidirectional spatial effect); STAR-U (spatio-temporal autoregressive model with unidirectional spatial effect)

This paper focuses on empirically determining the "optimal" temporal dimension, looking at the best model fit and predictive performance. The theory does not provide guidance on the exact specification of weight matrix regarding the STAR, STAR-U, and STAR-B models. The challenge of building the spatio-temporal weight matrices lies on 
two fronts. First, selecting a specification of the spatial relations (Chen, 2012) through spatial friction parameters to avoid the spatial over-connectivity bias (Smith, 2009). Second, the specifying the temporal relations that includes the simultaneous choice of temporal distance functional form, the temporal friction parameter value, and the temporal cut-off criteria, which are a function of the number of previous time periods included in the weight matrix $\underline{\mathbf{W}}$. For example, the temporal relations can be limited to only the previous time period $(t-1)$ or can be extended to a global temporal scale $(t-\theta$, $\vee \theta=1, \ldots, \Theta)$. Hence, one of the main research questions comes into focus: how can the optimal temporal distance be empirically determined.

\section{Methodological approach and data}

\subsection{Construction of the weight matrices}

This paper focuses on temporal effects ceteris paribus ${ }^{5}$, hence we need to specify a common for all models, yet flexible, spatial weight matrix. Chen (2012) provides a comprehensive discussion on the choice of the spatial weight matrix depending on the data scale and context. The individual spatial connections, $\mathrm{sij}_{\mathrm{j}}$, used to build the spatial weight matrix, are given in equation 7 .

$$
\mathrm{S}_{\mathrm{ij}}=\exp \left(-\mathrm{d}_{\mathrm{ij}}\right), \text { if } \mathrm{d}_{\mathrm{ij}} \leq \bar{d}_{\iota} \text { for all } \mathrm{i} \neq \mathrm{j}
$$

To avoid the over-connectivity problem, the critical distance cut-off point is adjusted for each individual observation $i$, as $\bar{d}_{\imath}$ is the mean distance of $i$ to all other observations. This ensures each observation has at least one spatial connection, the strength of which varies according to the dwelling density of the observation's location (Dunse et al., 2013).

\footnotetext{
${ }^{5}$ We test iteratively amplitudes of temporal distance over a number of different specifications. If we were to simultaneously test an equivalent iterative regime for spatial distance specification, then the combinations of the different options and hence models would be in the thousands. Hence, in this paper we have to rely on the theory, on past literature and similar application in this specific context for the best specification of the spatial weighting regime.
} 
The temporal distance is based on a general element, $\tau_{\mathrm{ij}}$, expressing the time elapsed between observations of $\mathrm{i}$ and $\mathrm{j}$ in equation 8 .

$$
\tau_{\mathrm{ij}}=\left(\mathrm{v}_{\mathrm{i}}-\mathrm{v}_{\mathrm{j}}\right)
$$

Where $\mathrm{v}_{\mathrm{i}}$ and $\mathrm{v}_{\mathrm{j}}$ are positive integers representing the time period when transactions $i$ and $j$ are observed. Thus, the value of $\tau_{\mathrm{ij}}$ is positive if $j<i$, or when observation $j$ was before observation $i$. The value of $\tau_{\mathrm{ij}}$ is 0 if observation $i$ and $\mathrm{j}$ are contemporaneous, while $\tau_{\mathrm{ij}}$ would be negative if $i$ was observed before $j$. The sign of the $\tau_{\mathrm{ij}}$ reflects the chronological order of the transactions: a positive value indicates a temporal unidirectional link from $j$ to $i$, and a zero value indicates cotemporaneous spatial influence. A negative value would indicate the impossible relationship of information exhibiting "time-travel". The latter, which is commonly employed in typical SAR models applied to housing transactions, is set to zero in our models. The information on the temporal distances is used to build the spatial weight matrices that capture the bidirectional spatial effect $(\mathbf{S})$ or unidirectional spatial effect $(\underline{\mathbf{W}})$.

Two types of the temporal distance transformation (or functional form) are tested for $\underline{\mathbf{W}}$. The inverse of the temporal distance, shown in equation 9, and the negative exponential transformation in equation 10. Both equations introduce the temporal cut-off criteria $\theta$, making possible to test the influence of a temporal "horizon" of past price information. We also test different values of $\gamma$ in equation 9, looking for the optimal temporal friction parameter. The temporal friction is set to negative exponential in equation 10.

$$
\begin{aligned}
& \tau_{\mathrm{ij}}{ }^{-\gamma} \text { if } \tau_{\mathrm{ij}}>0 \wedge\left(\mathrm{vi}_{\mathrm{i}}-\mathrm{v}_{\mathrm{j}}\right) \leq \theta \text { for all } \mathrm{i} \neq \mathrm{j} \\
& \exp \left[-\left(\tau_{\mathrm{ij}}\right)\right] \text { if } \tau_{\mathrm{ij}}>0 \wedge\left(\mathrm{v}_{\mathrm{i}}-\mathrm{v}_{\mathrm{j}}\right) \leq \theta \text { for all } \mathrm{i} \neq \mathrm{j}
\end{aligned}
$$

The elements of the weight matrix $\mathbf{S}$ express the contemporaneous spatial relations between observations and are given in equation 11 . 


$$
\mathrm{Sij}_{\mathrm{ij}}=\exp \left(-\mathrm{d}_{\mathrm{ij}}\right) \quad \text { if } \mathrm{d}_{\mathrm{ij}} \leq \mathrm{d}_{\mathrm{i}}^{*} \wedge \tau_{\mathrm{ij}}=0 \text { for all } \mathrm{i} \neq \mathrm{j}
$$

As discussed in section 2.1, the spatio-temporal relations are expressed using the Hadamard product of spatial and temporal distances $\left[\mathrm{w}_{\mathrm{ij}}=f\left(d_{i j}\right) \times f\left(\tau_{i j}\right)\right]$ (Dubé and Legros, 2014c; Dubé et al., 2014; Thanos et al., 2016).

\subsection{Empirical strategy}

In this section, we provide the empirical strategy of determining the best fitting model specification, and the optimal temporal distance friction and cut-off point. It is noted that the full sample is split in two sub-samples to allow out-of-sample estimation. Using the $1^{\text {st }}$ Sub-sample, the HP Base Model and STAR-U are estimated through Ordinary Least Squares (OLS), and STAR, and STAR-B models are estimated through Maximum Likelihood (ML).

First, we determine the optimal temporal friction parameter $\gamma$ through an iterative estimation process across a range of temporal cut-off $\theta$ values, by comparing the overall goodness of fit for STAR and STAR-U models in terms log-likelihood (LL). Having established an optimal $\gamma$, we compare the Base Model, STAR-B, STAR-U, and STAR for the best fit to the data across a range of $\theta$ s, by using Likelihood Ratio (LR) tests, looking at Akaike Information (AIC), and Bayesian Information criteria (BIC).

The process of out-of-sample estimation uses the second sub-sample to make predictions based on the already estimated parameters by the first sub-sample. The correlation between the predicted and actual values are calculated for each model, and these correlations are compared across different model specifications to arrive at the model with the highest prediction power. Having determined the best fitting model form (i.e. STAR, STAR-U, or STAR-B), we proceed to out-of-sample prediction, looking at the changes in prediction power of our preferred model form, when we compare the temporal transformations in equations 9 and 10 across a range of the temporal cut-off $\theta$ values. 


\subsection{Data}

The total sample available for estimation covers the housing market in Aberdeen, in North East Scotland and was provided by Aberdeen Solicitors Property Centre (Thanos and White, 2014). The data contains information on selling prices, structural characteristics of the property, and location. GIS was used to derive spatial variables such as distance to the central train station and the airport, dwelling density and socioeconomic characteristics on the level of census output area. The initial dataset contained 18,767 transactions where all the information on the variables is available across the city from 2004 to 2007.

To perform out-of-sample prediction, the total sample is first split in two sub-samples ${ }^{6}$. The models based on unidirectional spatial effect require that at least one time period is employed as a reference period. To ensure that $\underline{\mathbf{W}} \mathbf{y}$ is well defined, the first period of the sample is dropped from the estimation procedure in all data samples used for estimation and forecasting (Dubé et al., 2014; Dubé and Legros, 2014b; 2015).

The first sub-sample has 9,348 and the second 9,187 observations, after dropping 107 and 114 transactions respectively occurring in the first quarter of 2004, as shown in Table 1. A $\chi^{2}$ test cannot reject at the $99 \%$ level that the difference in temporal distribution between the two-subsamples is zero. Table 2 provides the descriptive statistics for all the data and the two subsamples.

\footnotetext{
${ }^{6}$ A random variable based on a uniform law is first created. If the value of the new variable is lower than 0.5 , than the observations are classify in the first sub-sample. Otherwise, the observations are classify in the second sub-sample.

${ }^{7} 11$ observations were dropped from estimation, due to being far outside the urban structure of Aberdeen.
} 
Table 1: Temporal distribution of the two sub-samples

\begin{tabular}{|c|c|c|c|c|}
\hline Months / Years & 2004 & 2005 & 2006 & 2007 \\
\hline \multicolumn{5}{|l|}{ Sub-sample 2} \\
\hline January & 16 & 121 & 124 & 127 \\
\hline February & 91 & 158 & 152 & 142 \\
\hline March & 178 & 229 & 188 & 207 \\
\hline April & 209 & 206 & 186 & 210 \\
\hline May & 226 & 245 & 239 & 257 \\
\hline June & 209 & 219 & 230 & 249 \\
\hline July & 216 & 221 & 239 & 246 \\
\hline August & 257 & 227 & 256 & 279 \\
\hline September & 196 & 216 & 214 & 209 \\
\hline October & 217 & 237 & 234 & 241 \\
\hline November & 222 & 212 & 209 & 231 \\
\hline December & 132 & 110 & 108 & 111 \\
\hline \multicolumn{5}{|l|}{ Sub-sample 2} \\
\hline January & 19 & 129 & 117 & 140 \\
\hline February & 95 & 156 & 138 & 133 \\
\hline March & 151 & 211 & 182 & 215 \\
\hline April & 173 & 185 & 167 & 204 \\
\hline May & 225 & 207 & 233 & 275 \\
\hline June & 213 & 215 & 267 & 237 \\
\hline July & 210 & 197 & 248 & 250 \\
\hline August & 200 & 195 & 267 & 273 \\
\hline September & 198 & 200 & 199 & 210 \\
\hline October & 223 & 269 & 246 & 230 \\
\hline November & 225 & 220 & 221 & 224 \\
\hline December & 115 & 127 & 132 & 143 \\
\hline
\end{tabular}


Table 2: Descriptive statistics Aberdeen data (2004-2007)

\begin{tabular}{|c|c|c|c|c|c|c|}
\hline \multirow[b]{2}{*}{ Variables } & \multicolumn{2}{|c|}{$\begin{array}{l}\text { Sub-sample } 1 \\
\left(\mathrm{~N}_{\mathrm{T}}: 9,348\right)\end{array}$} & \multicolumn{2}{|c|}{$\begin{array}{l}\text { Sub-sample } 2 \\
\left(\mathrm{~N}_{\mathrm{T}}: 9,187\right)\end{array}$} & \multicolumn{2}{|c|}{$\begin{array}{c}\text { Whole sample } \\
\left(\mathrm{N}_{\mathrm{T}}: 18,535\right)\end{array}$} \\
\hline & $\mu$ & $\sigma$ & $\mu$ & $\sigma$ & $\mu$ & $\sigma$ \\
\hline Sale Price (in $£$ ) & 141,756 & 103,491 & 143,693 & 102,972 & 142,716 & 103,236 \\
\hline Distance to airport $(\mathrm{km})$ & 7.6868 & 2.3060 & 7.7125 & 2.2983 & 7.6996 & 2.3022 \\
\hline Distance to central train station $(\mathrm{km})$ & 3.1245 & 2.4349 & 3.1463 & 2.4598 & 3.1353 & 2.4472 \\
\hline Detached houses & 0.0982 & 0.2976 & 0.1020 & 0.3027 & 0.1001 & 0.3001 \\
\hline Terraced or semi-detached house & 0.2679 & 0.4429 & 0.2662 & 0.4420 & 0.2671 & 0.4424 \\
\hline Basement flat & 0.0009 & 0.0292 & 0.0009 & 0.0295 & 0.0009 & 0.0294 \\
\hline 2nd floor flat & 0.0591 & 0.2357 & 0.0622 & 0.2414 & 0.0606 & 0.2386 \\
\hline 3rd floor flat & 0.0052 & 0.0722 & 0.0054 & 0.0736 & 0.0053 & 0.0729 \\
\hline 4th floor flat or higher & 0.0020 & 0.0450 & 0.0014 & 0.0376 & 0.0017 & 0.0415 \\
\hline Missing information - floor number of flat & 0.3373 & 0.4728 & 0.3378 & 0.4730 & 0.3375 & 0.4729 \\
\hline Houses with 1 bedrooms & 0.2888 & 0.4532 & 0.2756 & 0.4468 & 0.2823 & 0.4501 \\
\hline Houses with 2 bedrooms & 0.3810 & 0.4857 & 0.3949 & 0.4889 & 0.3879 & 0.4873 \\
\hline Houses with 4 bedrooms & 0.0686 & 0.2527 & 0.0730 & 0.2602 & 0.0708 & 0.2565 \\
\hline Houses with 5 bedrooms & 0.0209 & 0.1429 & 0.0188 & 0.1359 & 0.0199 & 0.1395 \\
\hline Houses with 6 bedrooms or more & 0.0071 & 0.0837 & 0.0073 & 0.0851 & 0.0072 & 0.0844 \\
\hline Missing bedroom number & 0.0121 & 0.1093 & 0.0108 & 0.1033 & 0.0114 & 0.1063 \\
\hline 3 or more public rooms & 0.0802 & 0.2717 & 0.0831 & 0.2760 & 0.0816 & 0.2738 \\
\hline 2 or more bathrooms & 0.0373 & 0.1896 & 0.0359 & 0.1861 & 0.0366 & 0.1879 \\
\hline House with garage(s) & 0.2131 & 0.4095 & 0.2187 & 0.4134 & 0.2159 & 0.4114 \\
\hline House with gas central heating & 0.7934 & 0.4049 & 0.7970 & 0.4023 & 0.7952 & 0.4036 \\
\hline House with garden & 0.5164 & 0.4998 & 0.5124 & 0.4999 & 0.5144 & 0.4998 \\
\hline$>50 \%$ detached houses & 0.0640 & 0.2447 & 0.0692 & 0.2539 & 0.0666 & 0.2493 \\
\hline$>50 \%$ terraced or semi-detached houses & 0.2716 & 0.4448 & 0.2702 & 0.4441 & 0.2709 & 0.4444 \\
\hline Not dominated from a specific house type & 0.0640 & 0.2447 & 0.0699 & 0.2550 & 0.0669 & 0.2499 \\
\hline$>50 \%$ of social rented houses & 0.0791 & 0.2698 & 0.0819 & 0.2742 & 0.0804 & 0.2720 \\
\hline$>50 \%$ of privately rented houses & 0.0190 & 0.1367 & 0.0187 & 0.1355 & 0.0189 & 0.1361 \\
\hline$>20 \%$ of vacant household spaces & 0.0594 & 0.2363 & 0.0582 & 0.2342 & 0.0588 & 0.2353 \\
\hline$>40 \%$ of the population over 60 & 0.0496 & 0.2172 & 0.0460 & 0.2096 & 0.0479 & 0.2135 \\
\hline$>60 \%$ of one person households & 0.2195 & 0.4139 & 0.2150 & 0.4108 & 0.2173 & 0.4124 \\
\hline$>30 \%$ of people (16-74) - no qualifications & 0,1792 & 0.3835 & 0.1781 & 0.3826 & 0.1786 & 0.3831 \\
\hline$>50 \%$ of the households owning 2 or + cars & 0.0758 & 0.2648 & 0.0802 & 0.2717 & 0.0780 & 0.2682 \\
\hline Dwelling density, dwellings per hectare & 49.4241 & 49.6942 & 48.3425 & 50.0849 & 48.8880 & 49.8898 \\
\hline
\end{tabular}




\section{Estimation Results}

This section discusses the estimation results, following the empirical strategy set in section 3.2.

\subsection{Model comparisons based on data fit}

Table 3 provides the results for Base Model and STAR-B, with AIC, BIC, and LL suggesting that latter is preferable to the former in terms of goodness of fit. The sign and magnitude of the coefficients are according to expectations from economic theory and the Base Model explains $80 \%$ of the variation in the data.

Table 3: HP estimation results for Base and STAR-B models using $1^{\text {st }}$ Sub-sample

\begin{tabular}{|c|c|c|c|c|}
\hline Dependent Variable: LN Sale price (£s) & \multicolumn{2}{|c|}{ Base Model } & \multicolumn{2}{|c|}{ STAR-B } \\
\hline Independent Variables & Coefficients & $\mathrm{p}$-value & Coefficients & p-value \\
\hline Constant & 11.4950 & 0.000 & 5.6129 & 0.000 \\
\hline Distance to airport in kilometres & 0.0107 & 0.000 & 0.0019 & 0.102 \\
\hline Distance to central train station in kilometres & -0.0330 & 0.000 & -0.0460 & 0.000 \\
\hline Detached houses & 0.1291 & 0.000 & 0.1554 & 0.000 \\
\hline Terraced or semi-detached house & 0.0391 & 0.001 & 0.0568 & 0.000 \\
\hline Ground floor flat & \multicolumn{2}{|c|}{ Reference } & \multicolumn{2}{|c|}{ Reference } \\
\hline 2nd floor flat & -0.0055 & 0.662 & -0.0037 & 0.752 \\
\hline 3rd floor flat & 0.0262 & 0.484 & 0.0336 & 0.340 \\
\hline 4th floor flat or higher & 0.0113 & 0.851 & 0.0413 & 0.466 \\
\hline Missing information on the floor number of flat & -0.0420 & 0.000 & -0.0420 & 0.000 \\
\hline Houses with 1 bedrooms & -0.5322 & 0.000 & -0.5198 & 0.000 \\
\hline Houses with 2 bedrooms & -0.1521 & 0.000 & -0.1481 & 0.000 \\
\hline Houses with 3 bedrooms & \multicolumn{2}{|c|}{ Reference } & \multicolumn{2}{|c|}{ Reference } \\
\hline Houses with 4 bedrooms & 0.2062 & 0.000 & 0.2061 & 0.000 \\
\hline Houses with 5 bedrooms & 0.3976 & 0.000 & 0.3827 & 0.000 \\
\hline Houses with 6 bedrooms or more & 0.6240 & 0.000 & 0.6087 & 0.000 \\
\hline Missing bedroom number & -0.8478 & 0.000 & -0.8347 & 0.000 \\
\hline 3 or more public rooms & 0.2672 & 0.000 & 0.2496 & 0.000 \\
\hline 2 or more bathrooms & 0.1378 & 0.000 & 0.1388 & 0.000 \\
\hline House with garage(s) & 0.1602 & 0.000 & 0.1281 & 0.000 \\
\hline
\end{tabular}




\begin{tabular}{|c|c|c|c|c|}
\hline \multirow{2}{*}{$\begin{array}{l}\text { Dependent Variable: LN Sale price (£s) } \\
\text { Independent Variables }\end{array}$} & \multicolumn{2}{|c|}{ Base Model } & \multicolumn{2}{|c|}{ STAR-B } \\
\hline & Coefficients & p-value & Coefficients & $\mathrm{p}$-value \\
\hline House with gas central heating & 0.1174 & 0.000 & 0.1057 & 0.000 \\
\hline House with garden & 0.0609 & 0.000 & 0.0584 & 0.000 \\
\hline$>50 \%$ detached houses & -0.0226 & 0.218 & -0.0686 & 0.000 \\
\hline$>50 \%$ terraced or semi-detached houses & -0.0115 & 0.247 & -0.0395 & 0.000 \\
\hline Not dominated from a specific house type & 0.0500 & 0.000 & 0.0246 & 0.037 \\
\hline$>50 \%$ of social rented houses & -0.1451 & 0.000 & -0.1296 & 0.000 \\
\hline$>50 \%$ of privately rented houses & -0.1440 & 0.000 & -0.1059 & 0.000 \\
\hline$>20 \%$ of vacant household spaces & -0.0461 & 0.000 & -0.0380 & 0.001 \\
\hline$>40 \%$ of the population over 60 & 0.1353 & 0.000 & 0.0993 & 0.000 \\
\hline$>60 \%$ of one person households & -0.0609 & 0.000 & -0.0679 & 0.000 \\
\hline$>30 \%$ of people (16-74) with no qualifications & -0.2629 & 0.000 & -0.2398 & 0.000 \\
\hline$>50 \%$ of the households owning 2 or + cars & 0.1854 & 0.000 & 0.1400 & 0.000 \\
\hline Dwelling density, dwellings per hectare & -0.0009 & 0.000 & -0.0009 & 0.000 \\
\hline $2004-\mathrm{Q} 1$ & \multicolumn{2}{|c|}{ Reference } & \multicolumn{2}{|c|}{ Reference } \\
\hline 2004 - Q2 & 0.0527 & 0.016 & 0.0014 & 0.947 \\
\hline $2004-$ Q3 & 0.0216 & 0.322 & -0.0037 & 0.856 \\
\hline 2004 - Q4 & 0.0289 & 0.192 & -0.0154 & 0.463 \\
\hline $2005-\mathrm{Q} 1$ & 0.0765 & 0.001 & 0.0236 & 0.267 \\
\hline 2005 - Q2 & 0.1436 & 0.000 & 0.0331 & 0.111 \\
\hline $2005-\mathrm{Q} 3$ & 0.1411 & 0.000 & 0.0424 & 0.041 \\
\hline $2005-\mathrm{Q} 4$ & 0.1628 & 0.000 & 0.0527 & 0.013 \\
\hline 2006 - Q1 & 0.2527 & 0.000 & 0.1074 & 0.000 \\
\hline $2006-\mathrm{Q} 2$ & 0.3543 & 0.000 & 0.1431 & 0.000 \\
\hline 2006 - Q3 & 0.4042 & 0.000 & 0.1692 & 0.000 \\
\hline 2006 - Q4 & 0.4638 & 0.000 & 0.2173 & 0.000 \\
\hline 2007 - Q1 & 0.6129 & 0.000 & 0.2945 & 0.000 \\
\hline 2007 - Q2 & 0.6904 & 0.000 & 0.3048 & 0.000 \\
\hline 2007 - Q3 & 0.6646 & 0.000 & 0.2950 & 0.000 \\
\hline 2007 - Q4 & 0.6342 & 0.000 & 0.2886 & 0.000 \\
\hline Spatial autoregressive effect $(\rho)$ & & & 0.5307 & 0.000 \\
\hline $\mathrm{R}^{2} /$ Adjusted $\mathrm{R}^{2}$ & \multicolumn{2}{|c|}{$0.8009 / 0.7999$} & & \\
\hline Log-likelihood (LL) & \multicolumn{2}{|c|}{-587.117} & \multicolumn{2}{|c|}{-88.050} \\
\hline Akaike Information Criteria (AIC) & \multicolumn{2}{|c|}{$1,266.234$} & \multicolumn{2}{|c|}{272.1002} \\
\hline Bayesian Information Criteria (BIC) & \multicolumn{2}{|c|}{$1,594.809$} & \multicolumn{2}{|c|}{614.9603} \\
\hline $\operatorname{MSE}\left(\sigma^{2}\right)$ & \multicolumn{2}{|c|}{0.067} & \multicolumn{2}{|c|}{0.059} \\
\hline $\mathrm{N}_{\mathrm{T}} / \mathrm{K}$ & \multicolumn{2}{|c|}{$9,348 / 45$} & \multicolumn{2}{|c|}{$9,348 / 46$} \\
\hline
\end{tabular}


The results of the iterative estimation process to determine the optimal temporal friction parameter $\gamma$ across a range of temporal cut-off $\theta$ values are presented in Figures 2 and 3 for STAR-U and STAR models respectively. The results are striking and consistent for both models. The goodness of fit is not improved beyond a $\theta$ of 8 months, but optimal $\gamma$ is very close to zero (0.05). This denotes that information from past transactions stops contributing to the price determination process after the elapse of 8 months. More importantly, there is almost no temporal friction for the price information within the 8 months' time-horizon.

Figure 2: Optimal values of $\theta$ and $\gamma$ for STAR-U model

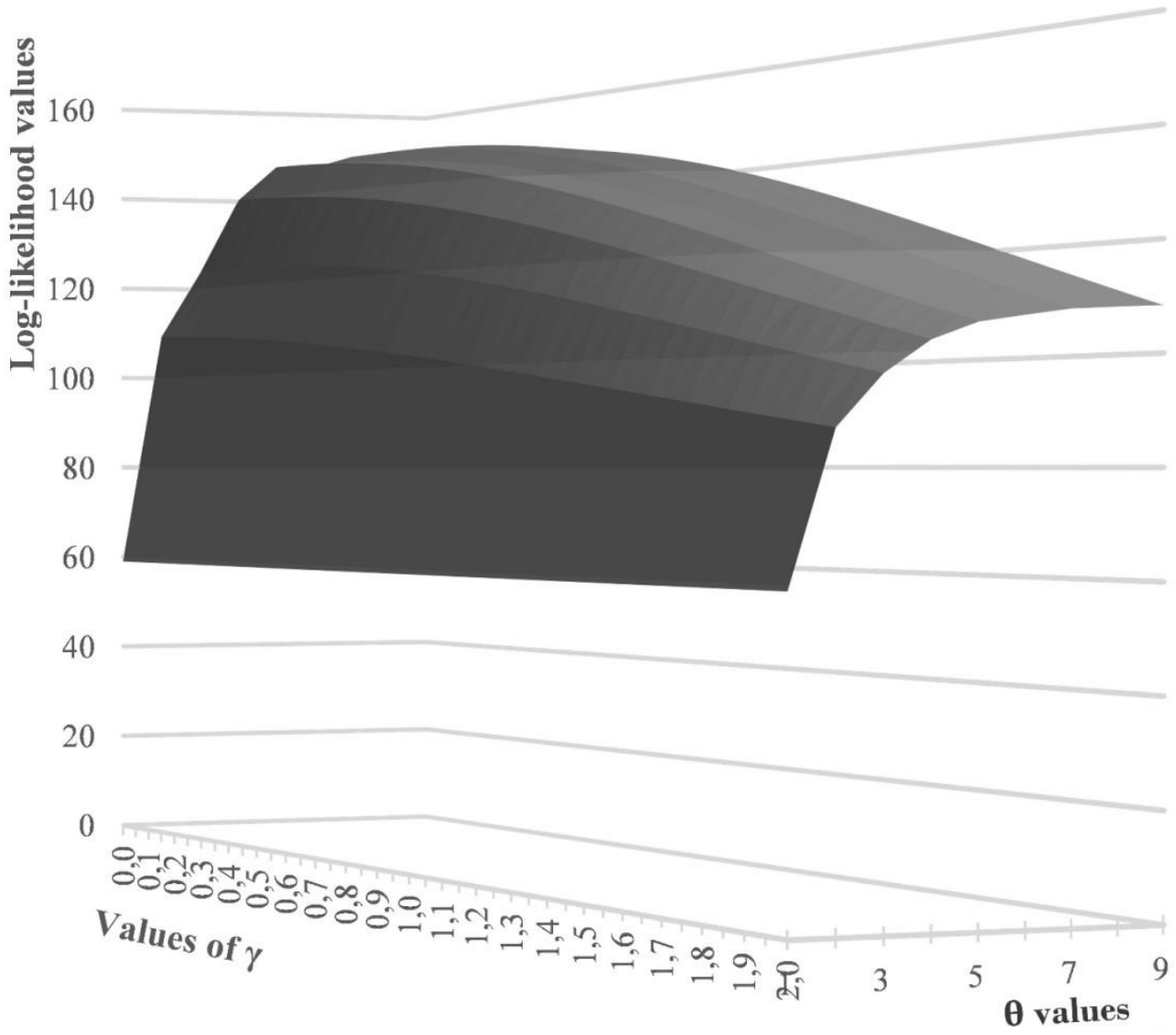


Figure 3: Optimal values of $\theta$ and $\gamma$ for STAR model

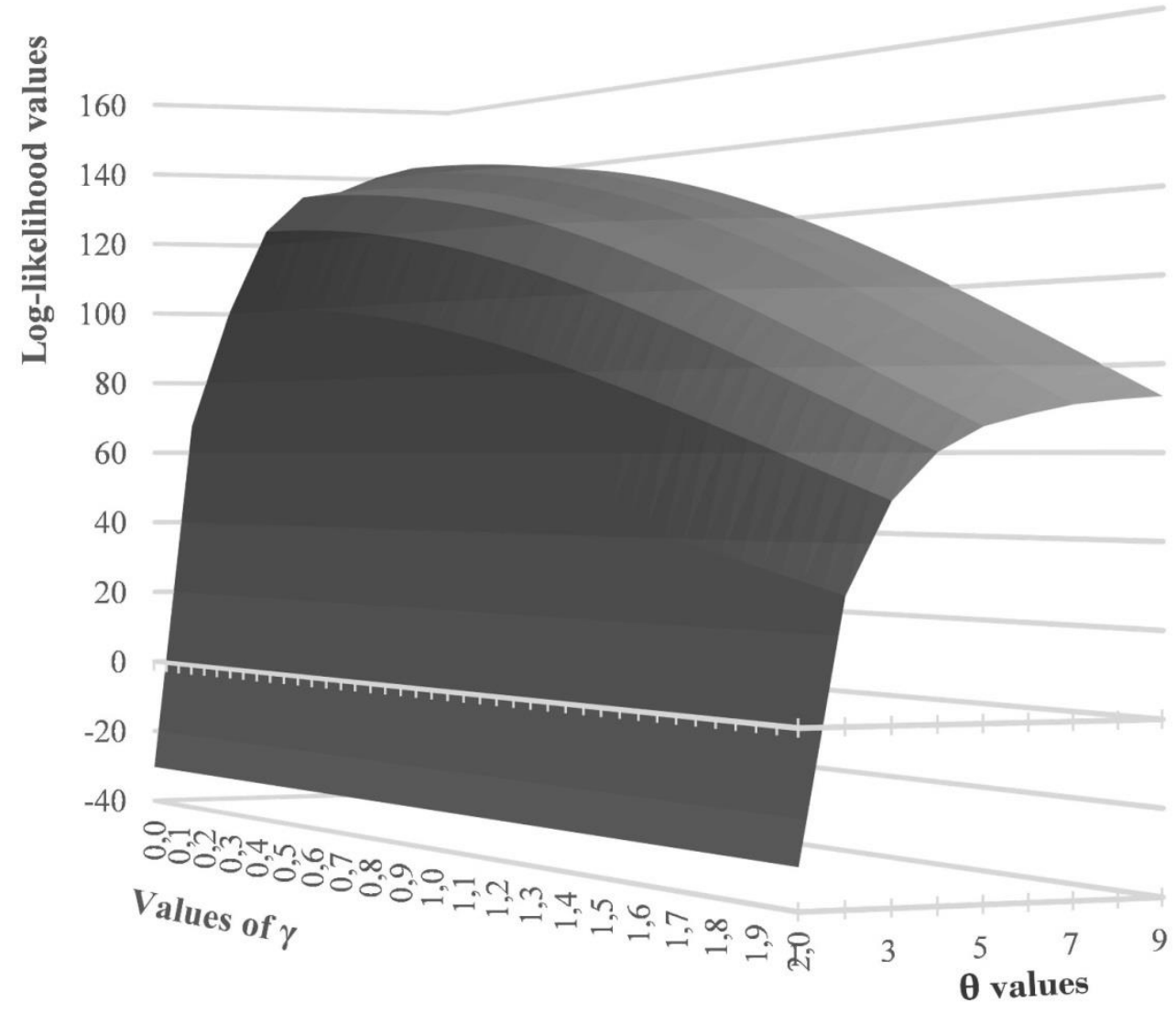

Having determined an optimal $\gamma$ of 0.05 for STAR-U and STAR, we proceed to compare the goodness of fit across specifications. The AIC, BIC and LL in Tables 3, 4 and 5 suggest that STAR-U exhibits better fit to the data than STAR-B and the base model across the board. Hence, the dominant spatial connection appears not to be the contemporaneous "peer" effect, as it is typically assumed in strictly spatial econometrics models, but the unidirectional spatio-temporal connections conceptualized as the comparable sales approach. The LR tests in Tables 4 and 5 demonstrate that a STAR specification including both $\rho$ and $\psi$ improves goodness-of-fit at the $99 \%$ level of significance compared to all STAR-U and STAR-B specifications. Hence, the unidirectional spatial effect is quite an important component to explain price determination process, a conclusion that was reached in a similar exercise for Paris real estate data between 1990 and 2001 (Dubé and Legros, 2014b). It is also clearly demonstrated that it is preferable to include in the modelling process both peer effect and comparable sales. 
Table 4: Iterative estimation for optimal temporal distance cut-off point $(\theta)$ under inverse transformation and $\gamma=0.05\left(\tau_{i j}^{-0.05}\right)$

\begin{tabular}{|c|c|c|c|c|c|c|c|c|c|}
\hline Models & & & & Numl & per of mont & hs $(\theta)$ & & & \\
\hline STAR-U (Equation 3 - $\underline{\mathbf{W}})$ & 1 & 2 & 3 & 4 & 5 & 6 & 7 & 8 & 9 \\
\hline Physical \& Environmental & & & & & & & & & \\
\hline Amenities & Yes & Yes & Yes & Yes & Yes & Yes & Yes & Yes & Yes \\
\hline Quarter (time) dummies & Yes & Yes & Yes & Yes & Yes & Yes & Yes & Yes & Yes \\
\hline$\psi$ & 0.6230 & 0.7132 & 0.7460 & 0.7683 & 0.7768 & 0.7772 & 0.7815 & 0.7824 & 0.7796 \\
\hline AIC & 154.60 & -40.74 & -106.68 & -153.75 & -174.23 & -177.84 & -186.84 & -192.75 & -189.85 \\
\hline BIC & 490,31 & 294.98 & 229.04 & 181.97 & 161.48 & 157.88 & 148.88 & 142.97 & 145.87 \\
\hline LL & -30.30 & 67.37 & 100.34 & 123.87 & 134.12 & 135.92 & 140.42 & 143.37 & 141.92 \\
\hline STAR (Equation $6-\underline{\mathbf{W}}$ and $\mathbf{S}$ ) & 1 & 2 & 3 & 4 & 5 & 6 & 7 & 8 & 9 \\
\hline Physical \& Environmental & & & & & & & & & \\
\hline Amenities & Yes & Yes & Yes & Yes & Yes & Yes & Yes & Yes & Yes \\
\hline Quarter (time) dummies & Yes & Yes & Yes & Yes & Yes & Yes & Yes & Yes & Yes \\
\hline$\psi$ & 0.4075 & 0.5339 & 0.5947 & 0.6367 & 0.6542 & 0.6601 & 0.6716 & 0.6800 & 0.6773 \\
\hline$\rho$ & 0.2963 & 0.2165 & 0.1712 & 0.1450 & 0.1339 & 0.1272 & 0.1183 & 0.1097 & 0.1097 \\
\hline AIC & -21.97 & -122.29 & -151.68 & -184.31 & -199.67 & -200.10 & -205.42 & -208.05 & -205.09 \\
\hline $\mathrm{BIC}$ & 320,89 & 220.57 & 191.18 & 158.55 & 143.19 & 142.76 & 137.44 & 134.81 & 137.77 \\
\hline LL & 58.99 & 109.15 & 123.84 & 140.16 & 147.83 & 148.05 & 150.71 & 152.03 & 150.55 \\
\hline LR statistic (STAR vs STAR-U) & $178.6 * * *$ & $83.6^{* * *}$ & $47.0^{* * *}$ & $32.6^{* * *}$ & $27.4^{* * *}$ & $24.3 * * *$ & $20.6^{* * *}$ & $17.3^{* * *}$ & $17.3 * * *$ \\
\hline LR statistic (STAR vs STAR-B) & $294.1 * * *$ & $394.4 * * *$ & $423.8 * * *$ & $456.4 * * *$ & $471.8 * * *$ & $472.2 * * *$ & $477.5 * * *$ & $480.2 * * *$ & $477.2 * * *$ \\
\hline
\end{tabular}

$* * * \mathrm{p}<0.01 ; * * \mathrm{p}<0.05$, we use the 1 st Sub-sample for this estimation. 
Table 5: Iterative estimation for optimal temporal distance cut-off point $(\mathrm{p})$ under negative exponential transformation $\left(\exp \left(-\tau_{\mathrm{ij}}\right)\right)$

\begin{tabular}{|c|c|c|c|c|c|c|c|c|c|}
\hline \multirow{2}{*}{$\begin{array}{l}\text { Models } \\
\text { STAR-U (Equation } 3-\underline{\mathbf{W}})\end{array}$} & \multicolumn{9}{|c|}{ Number of months $(\theta)$} \\
\hline & 1 & 2 & 3 & 4 & 5 & 6 & 7 & 8 & 9 \\
\hline \multicolumn{10}{|l|}{ Physical \& Environmental } \\
\hline Amenities & Yes & Yes & Yes & Yes & Yes & Yes & Yes & Yes & Yes \\
\hline Quarter (time) dummies & Yes & Yes & Yes & Yes & Yes & Yes & Yes & Yes & Yes \\
\hline$\psi$ & 0.6230 & 0.6936 & 0.7131 & 0.7197 & 0.7218 & 0.7223 & 0.7226 & 0.7226 & 0.7227 \\
\hline AIC & 154.60 & 7.70 & -33.74 & -48.32 & -52.93 & -54.14 & -54.67 & -54.80 & -54.84 \\
\hline $\mathrm{BIC}$ & 490.31 & 343.41 & 301.98 & 287.40 & 282.78 & 281.58 & 281.04 & 280.92 & 280.87 \\
\hline LL & -30.30 & 43.15 & 63.87 & 71.16 & 73.47 & 74.07 & 74.34 & 74.40 & 74.42 \\
\hline STAR (Equation $6-\underline{\mathbf{W}}$ and $\mathbf{S}$ ) & 1 & 2 & 3 & 4 & 5 & 6 & 7 & 8 & 9 \\
\hline \multicolumn{10}{|l|}{ Physical \& Environmental } \\
\hline Amenities & Yes & Yes & Yes & Yes & Yes & Yes & Yes & Yes & Yes \\
\hline Quarter (time) dummies & Yes & Yes & Yes & Yes & Yes & Yes & Yes & Yes & Yes \\
\hline$\psi$ & 0.4075 & 0.5018 & 0.5332 & 0.5443 & 0.5478 & 0.5488 & 0.5493 & 0.5494 & 0.5494 \\
\hline$\rho$ & 0.2963 & 0.2371 & 0.2150 & 0.2077 & 0.2053 & 0.2045 & 0.2042 & 0.2041 & 0.2041 \\
\hline AIC & -21.97 & -93.33 & -112.57 & -120.82 & -123.43 & -123.99 & -124.28 & -124.33 & -124.35 \\
\hline $\mathrm{BIC}$ & 320.89 & 249.53 & 230.29 & 222.04 & 219.43 & 218.87 & 218.58 & 218.53 & 218.51 \\
\hline LL & 58.99 & 94.66 & 104.28 & 108.41 & 109.71 & 110.00 & 110.14 & 110.16 & 110.17 \\
\hline LR statistic (STAR vs STAR-U) & $178.6^{* * *}$ & $103.0 * * *$ & $80.8^{* * *}$ & $74.5^{* * *}$ & $72.5^{* * *}$ & $71.9^{* * *}$ & $71.6^{* * *}$ & $71.5 * * *$ & $71.5 * * *$ \\
\hline LR statistic (STAR vs STAR-B) & $294.1 * * *$ & $365.4 * * *$ & $384.7 * * *$ & $392.9 * * *$ & $395.5 * * *$ & $396.1 * * *$ & $396.4^{* * *}$ & $396.4 * * *$ & $396.5^{* * *}$ \\
\hline
\end{tabular}


The STAR (and STAR-U) specification in Table 4 shows the optimal temporal horizon $\theta$ is 8 months, when employing the inverse temporal distance format, consistent with Figures 2 and 3. Even though LL flattens out after 7 months in Table 5 similarly to Table 4 , there are minimal goodness of gains even at a 9 months $\theta$. AIC, BIC, and LL show the inverse temporal distance (equation 9) specification in Table 4 to fit the data better than the negative exponential (equation 10) Table 5. However, we cannot conduct LR tests between the two specifications, as no extra parameters are directly estimated. Therefore, out-of-sample prediction exercise on STAR is employed in the next section to further examine and validate which of the two specifications of temporal friction provide better prediction power.

\subsection{Out-of-sample prediction of the temporal specification and cut-off point}

As discussed in section 3.2, when conducting out-of-sample estimation, the second subsample is used to make predictions based on the estimated parameters by the first subsample. The predicted values are then compared with the observed values and the correlation between the two is calculated. A specification is considered better if the outof-sample performance measured by the correlation is higher using the reduced form of the specification ${ }^{8}$. We proceed to out-of-sample estimation, looking at the changes in prediction power of STAR, when we compare the temporal transformations in equations 9 and 10 across a range of the temporal cut-off $\theta$ values

Table 6 shows the optimal time cut-off $\theta$ to be 5 months for the negative exponential (equation 10) and 8 months for inverse temporal transformation (equation 9). Consistent with the estimation results in the previous section, the inverse temporal transformation produces higher correlation values in Table 6 than negative exponential transformation, denoting higher predictive power. Hence, this is our preferred specification showing that information from sales further than 8 months in the past does not contribute to the price determination process.

\footnotetext{
${ }^{8}$ The predicted sale price $\hat{y}$ is calculated using the estimated coefficients $(\beta, \rho, \psi)$ from the first sub-sample and the reduced form of the appropriate data generating process (DGP) postulated.
} 
Table 6: Out-of-sample estimation: correlation between predicted and observed values

\begin{tabular}{lcc|cc}
\hline STAR Model & \multicolumn{3}{c}{$\underline{\mathbf{W}}$ and S (Equation 6) } \\
\hline Specification of $\underline{\mathbf{W}}$ & \multicolumn{2}{c}{$\exp \left(-\tau_{\mathrm{ij}}\right)$} & \multicolumn{2}{c}{$\tau_{\mathrm{ij}}{ }^{-0.05}$} \\
\hline$\theta$ (No of months) & Correlation & RMSE & Correlation & RMSE \\
\hline 1 month & 0.9022 & 0.0621 & 0.9022 & 0.0621 \\
2 months & 0.9051 & 0.0604 & 0.9060 & 0.0598 \\
3 months & 0.9058 & 0.0599 & 0.9072 & 0.0591 \\
4 months & 0.9061 & 0.0597 & 0.9080 & 0.0586 \\
5 months & 0.9062 & 0.0597 & 0.9083 & 0.0584 \\
6 months & 0.9062 & 0.0597 & 0.9085 & 0.0583 \\
7 months & 0.9062 & 0.0597 & 0.9086 & 0.0582 \\
8 months & 0.9062 & 0.0597 & 0.9088 & 0.0581 \\
9 months & 0.9062 & 0.0597 & 0.9087 & 0.0581 \\
\hline
\end{tabular}

\subsection{Correlations between spatial and spatio-temporal matrices}

A corollary issue is underlined by LeSage and Pace (2014) as the "biggest myth of spatial econometrics", which lies on the misconception that a small change in the construction of the weight matrix will translate to significant changes in the results. They argue that different types of spatial weight matrices are typically highly correlated with each other. They proceed to demonstrate that varying the number of nearest neighbours and comparing it to a contiguity weight matrix has limited effect on correlation that substantially exceeds 0.5 between the two types of matrices. We follow their approach to test whether accounting for the temporal dimension in the weight matrix construction reduces the correlation between the different matrix specifications.

The results in Table 7 show that the full spatial weight matrix $\mathbf{W}$ is weakly correlated with $\mathbf{S}$, and $\underline{\mathbf{W}}$. The correlation between $\mathbf{W}$ and $\mathbf{S}$ is 0.135 , while the correlation between $\mathbf{W}$ and the spatio-temporal matrix $\underline{\mathbf{W}}$ ranges between 0.15 and 0.42 . Moreover, the correlations between the block diagonal structure $\mathbf{S}$ and the lower triangular $\underline{\mathbf{W}}$ specifications are close to zero. It is evident that the STAR configuration has low overall correlation to all the full spatial weight matrix. Hence, inserting the temporal dimension into typical spatial weight matrices introduces significant variability of information and moves of away from the conditions of the "biggest myth of spatial econometrics" (LeSage and Pace, 2014). 
Table 7: Correlation between spatial and spatiotemporal weights matrices

\begin{tabular}{|c|c|c|c|c|c|}
\hline \multirow{2}{*}{$\begin{array}{l}\text { Weight matrices }{ }^{\dagger} \\
\text { Sub-sample } 1 \\
\end{array}$} & \multicolumn{2}{|c|}{ Correlation } & \multicolumn{3}{|c|}{ Number of neighbours } \\
\hline & $\begin{array}{c}\mathbf{W} \\
\text { (spatial full } \\
\text { symmetric ) } \\
\end{array}$ & $\begin{array}{c}\mathbf{S} \\
\text { (spatial block } \\
\text { diagonal) } \\
\end{array}$ & Mean & Min & $\operatorname{Max}$ \\
\hline $\mathbf{S}$ (spatial block diagonal) & 0.1347 & 1.0000 & 124 & 38 & 182 \\
\hline$\underline{\mathbf{W}}$ (lower triangular, $\theta=1$ ) & 0.1497 & 0.0313 & 122 & 36 & 184 \\
\hline$\underline{\mathbf{W}}$ (lower triangular, $\theta=2$ ) & 0.1957 & 0.0084 & 240 & 40 & 352 \\
\hline$\underline{\mathbf{W}}$ (lower triangular, $\theta=3$ ) & 0.2392 & 0.0298 & 353 & 40 & 502 \\
\hline$\underline{\mathbf{W}}$ (lower triangular, $\theta=4$ ) & 0.2804 & 0.0080 & 462 & 40 & 669 \\
\hline$\underline{\mathbf{W}}$ (lower triangular, $\theta=5$ ) & 0.3359 & -0.0122 & 566 & 40 & 814 \\
\hline$\underline{\mathbf{W}}$ (lower triangular, $\theta=6$ ) & 0.3557 & -0.0188 & 667 & 40 & 964 \\
\hline$\underline{\mathbf{W}}$ (lower triangular, $\theta=7$ ) & 0.3895 & -0.0166 & 765 & 40 & 1,107 \\
\hline$\underline{\mathbf{W}}$ (lower triangular, $\theta=8$ ) & 0.4058 & -0.0080 & 861 & 40 & 1,224 \\
\hline$\underline{\mathbf{W}}$ (lower triangular, $\theta=9$ ) & 0.4242 & 0.0129 & 955 & 40 & 1,362 \\
\hline \multicolumn{6}{|c|}{ Sub-sample 2 ( used for out-of-sample estimation) } \\
\hline $\mathbf{S}$ (spatial block diagonal) & 0.1421 & 1.0000 & 122 & 35 & 195 \\
\hline$\underline{\mathbf{W}}$ (lower triangular, $\theta=1$ ) & 0.1595 & -0.0486 & 119 & 36 & 192 \\
\hline$\underline{\mathbf{W}}$ (lower triangular, $\theta=2$ ) & 0.1950 & -0.0202 & 235 & 46 & 358 \\
\hline$\underline{\mathbf{W}}$ (lower triangular, $\theta=3$ ) & 0.2399 & 0.0011 & 346 & 46 & 533 \\
\hline$\underline{\mathbf{W}}$ (lower triangular, $\theta=4$ ) & 0.2634 & 0.0136 & 453 & 46 & 688 \\
\hline$\underline{\mathbf{W}}$ (lower triangular, $\theta=5$ ) & 0.2809 & 0.0254 & 556 & 46 & 830 \\
\hline$\underline{\mathbf{W}}$ (lower triangular, $\theta=6$ ) & 0.2911 & 0.0076 & 656 & 46 & 982 \\
\hline$\underline{\mathbf{W}}$ (lower triangular, $\theta=7$ ) & 0.3009 & -0.0009 & 753 & 46 & 1,131 \\
\hline$\underline{\mathbf{W}}$ (lower triangular, $\theta=8$ ) & 0.3071 & -0.0101 & 848 & 46 & 1,229 \\
\hline$\underline{\mathbf{W}}$ (lower triangular, $\theta=9$ ) & 0.3122 & -0.0014 & 941 & 46 & 1,372 \\
\hline
\end{tabular}

$\uparrow$ The weight matrices are multiplied by the vector $\mathbf{u}$ in calculating correlation, where $\mathbf{u}$ is a vector of random numbers $(\mathrm{N}(0,1))$ according to Lesage and Pace (2014). $\gamma=0.05$ for the exercise

Summarizing, the novelty of our research approach, extending the Dubé and Legros (2013a; 2014a) and Thanos et al., (2016) approaches, is underlined by the flowing unique findings: i) the model results clearly show that the two spatio-temporal components, the bidirectional "peer" and unidirectional "comparable sales" connections, should be included in the specification, reinforcing the theoretical underpinnings; ii) the spatial bidirectional weight matrix $(\mathbf{S})$ and the unidirectional weight matrix $(\underline{\mathbf{W}})$ clearly return different results to the full spatial weight matrix $(\mathbf{W})$, as illustrated by the very low correlation, addressing the concerns in LeSage and Pace (2014); iii) the optimal temporal 
horizon (cut-off) is around 8 months, beyond which information is heavily discounted and does not improve the overall model fit; and iv) the inverse temporal transformation works best for constructing spatio-temporal weight matrices with a very low, close to zero, temporal friction $\gamma$. Thus, at least in the case of Aberdeen, we underline the nonlinearities of the temporal aspect in the price determination process.

\section{Conclusions}

This paper specified and compared different versions of the STAR model that account for temporal constraints on spatial relations, improving the performance of the HP model. The empirical analysis is based on a case study of real estate transactions in Aberdeen, Scotland. Different models, temporal distance transformations, friction parameters, and cut-off points were tested and compared, in order to conclude to an overall optimal specification. The approach included an out-of-sample estimation by decomposing the sample of 18,535 observations into two sub-samples.

The results regarding the performance of the models according to the choice of the weight matrix are not unique in the literature (Dubé and Legros, 2014a, 2014b, 2013a, 2013b). However, this is the first time that in conjunction with best data-fit comparisons and statistical tests between competing specifications, a formal out-of-sample prediction approach is proposed to determine optimal temporal distance lengths and transformations. This work contributes to the body of proof that real estate modelling needs to account for the particularity of transaction data regarding the temporal aspects of seemingly spatial relations.

The paper demonstrates that the spatial relations are more complex than the contemporaneous "peer" effect, routinely captured through strictly spatial weight matrices in the literature. The results clearly show that the two spatio-temporal components, bidirectional "peer" and unidirectional "comparable sales", should be both included in STAR HP models. The configuration of spatio-temporal weight matrices in 
STAR also exhibits very low correlation to the misspecified spatial weights in SAR, and hence the high variability of spatio-temporal information. Furthermore, the dominant spatial connection appears not to be the contemporaneous "peer" effect, as it is typically assumed in strictly spatial econometrics models, but the unidirectional spatio-temporal connections conceptualized as the comparable sales approach.

This suggest that the "comparable sales approach" used by the real estate professionals is a well internalized process for price determination. However, the complete spatiotemporal scheme proposed here underlines the misgivings of real estate appraisal frameworks that are based on arbitrary time-horizons and spatio-temporal "friction". The findings here denote that information on transactions stops contributing to the price determination process after the elapse of 8 months. The inverse temporal transformation works better that the negative exponential, showing very limited spatio-temporal friction (or decay) within the 8 month time-horizon of our data.

This result might be seen to attribute a fairly limited "memory" to the market. While the conclusion of this paper does not systematically extend to other data and contexts, the suggested methodology provides interesting opportunities for comparisons in future research. In a very recent study, Hyun and Milcheva (2016) find that the spatio-temporal effect of past price information changes in boom and recession conditions in Korea. However, they only assume a 6 months information decay amplitude, instead of testing it. The time horizon of past price information could be one of the key changes in boom and recession periods, along with the magnitude of the effect, as heuristics and anchoring, lagged responses, and behavioural biases affect housing consumers' attitudes (Scott and Lizieri, 2012; Haurin et al., 2013; Thanos and White, 2014).

More work is required to develop and disseminate modelling tools for spatial/spatiotemporal connections (bidirectional and unidirectional) in real estate. The extension of this approach from STAR to models that include spatio-temporal error terms is one avenue of further research. The limitation of determining the optimal spatial specification (Vega and Elhorst, 2015) simultaneously to the optimal temporal specification 
determination highlights the need for further development in processes and algorithms for efficient selection and combination of spatial and temporal distances. We hope that this application will spur practitioners and academics to develop appropriate tools for dealing with spatial data with temporal dimension.

\section{References}

Can, A. (1992). Specification and Estimation of Hedonic Housing Price Models, Regional Science and Urban Economics, 22(3): 453-474.

Can, A., \& Megbolugbe, I. (1997). Spatial dependence and house price index construction, Journal of Real Estate Finance and Economics, 14: 203-222.

Case, K.E. \& Shiller, R.J. (1989). The Efficiency of the Market for Single-Family Homes, American Economic Review, 79: 125-137.

Case, K.E. \& Shiller, R.J. (1987). Prices of Single-Family Homes since 1970: New Indexes for Four Cities, New England Economic Review: September/October.

Case, B., Pollakowski, H.O. \& Wachter, S.M. (1991). On Choosing Among House Price Index Methodologies. Real Estate Economics, 19: 286-307

Chen, Y. (2012). On the Four Types of Weight Functions for Spatial Contiguity Matrix, Letters in Spatial and Resource Sciences, 5: 65-72.

Clapp, J.M. \& Giacotto, C. (1992). Estimating Price Trends for Residential Property: A Comparison of Repeat Sales and Assessed Value Methods, Journal of Real Estate Finance and Economics, 5: 357-374.

Des Rosiers, F., Dubé, J. \& Thériault, M. (2011). Do Peer Effects Shape Property Values?, Journal of Property Investment and Finance, 29(4/5): 510-528.

Dubé, J. \& Legros, D. (2015). Modeling Spatial Data Pooled over Time: Schematic Representation and Monte Carlo Evidences, Theoretical Economics Letters, 5: 132154.

Dubé, J. \& Legros, D. (2014a) Spatial Econometrics and Spatial Data Pooled over Time: Towards an Adapted Modelling Approach, Journal of Real Estate Literature, 22(1): 101-125. 
Dubé, J. \& Legros, D. (2014b) Spatial Econometrics and the Hedonic Pricing Model: What About the Temporal Dimension?, Journal of Property Research, 31(4): 333-359.

Dubé, J. \& Legros, D. (2014c). Spatial Econometrics using Microdata, John Wiley and Sons inc., London.

Dubé, J. \& Legros, D. (2013a) A Spatio-temporal Measure of Spatial Dependence: An Example Using Real Estate Data, Papers in Regional Science, 92(1): 19-30.

Dubé, J. \& Legros, D. (2013b). Dealing with Spatial Data Pooled over Time in Statistical Models, Letters in Spatial and Resource Sciences, 6(1): 1-18.

Dubé, J., Baumont, C. \& Legros, D. (2013). Matrices de pondérations et contexte spatiotemporel en économétrie spatiale, Revue canadienne de science régionale, 36(1/3): $57-75$.

Dubé, J., Legros, D., Thériault, M. \& Des Rosiers, F (2017). Measuring and Interpreting Urban Externalities in Real-Estate Data: A Spatio-Temporal Difference-in-Differences (STDID) Estimator, Buildings, 7(51): 23 p. (doi:10.3390/buildings7020051)

Dubé, J., Legros, D., Thériault, M. \& Des Rosiers, F (2014). A Spatial Difference-inDifferences Estimator to Evaluate the Effect of Change in Public Mass Transit Systems on House Prices, Transportation Research Part B, 64: 24-40.

Dunse, N., Thanos, S., \& Bramley, G., (2013). Planning Policy, Housing Density and Consumer Preferences, Journal of Property Research, 30: 221-238.

Elhorst, J.P. (2014). Spatial Econometrics: From Cross-Sectional Data to Spatial Panels, Springer Briefs in Regional Science, Springer.

Gibbons, S. \& Overman, H.G. (2012). Mostly Pointless Spatial Econometrics?, Journal of Regional Science, 52: 172-191.

Gibbons, S., Overman, H.G. \& Patacchini (2014). Spatial Methods, SERC Discussion Paper 162, $68 \mathrm{p}$.

Huang, B., Wu, B. \& Barry, M. (2010). Geographically and Temporally Weighted Regression for Modelling Spatiotemporal Variation in House Prices, International Journal of Geographical Information Science, 24(3), 383-401.

Isakson, H.R., (2002). The Linear Algebra of the Sales Comparison Approach, Journal of Real Estate Research, 24, 117-128. 
Kim, C.W., Phipps, T.T., Anselin, L., (2003). Measuring the benefits of air quality improvement: a spatial hedonic approach. Journal of environmental economics and management, 45, 24-39.

LeSage, J.P. (2014). What Regional Scientists Need to Know about Spatial Econometrics, The Review of Regional Studies, 44: 13-32.

LeSage, J.P. \& Pace, R.K. (2014). The Biggest Myth in Spatial Econometrics, Econometrics, 2: 217-249.

LeSage, J.P. \& Pace, R.K. (2011). Pitfalls in Higher Order Model Extensions of Basic Spatial Regression Methodology, The Review of Regional Studies, 41: 13-26.

LeSage, J.P. \& Pace, R.K. (2009). Introduction to spatial econometrics. NY: CRC Press, New York, US.

Nase, I., Berry, J., Adair, A. (2016). Impact of quality-led design on real estate value: a spatiotemporal analysis of city centre apartments. Journal of Property Research, 33 (4), $309-331$

Pace, R.K., Barry, R., Clapp, J.M. \& Rodriquez, M. (1998). Spatiotemporal Autoregressive Models of Neighborhood Effects, Journal of Real Estate Finance and Economics, 17: 15-33.

Rosen, S. (1974). Hedonic Prices and Implicit Markets: Product Differentiation in Pure Competition, Journal of Political Economy, 82(1): 34-55.

Small, K. A. \& Steimetz, S.S.C. (2012). Spatial Hedonics and the Willingness to Pay for Residential Amenities, Journal of Regional Science, 52, 635-647.

Smith, T.E. (2009). Estimation Bias in Spatial Models with Strongly Connected Weight Matrices, Geographical Analysis, 41, 307-33.

Smith, T.E. \& Wu, P. (2009). A Spatio-temporal Model of Housing Prices based on Individual Sales Transactions over Time, Journal of Geographical Systems, 11: 333355.

Thanos, S., Bristow A.L. \& Wardman, M.R. (2015), Residential Sorting and Environmental Externalities: The Case of non-linearities and Stigma in Aviation Noise Values, Journal of Regional Science, 55(3): 468-490 
Thanos, S., Bristow, A.L., \& Wardman, M.R. (2012). Theoretically Consistent Temporal Ordering Specification in Spatial Hedonic Pricing Models Applied to the Valuation of Aircraft Noise, Journal of Environmental Economics and Policy, 1(2), 103-126.

Thanos, S., Dubé, J., \& Legros, D. (2016). Putting Time into Space: The Temporal Coherence of Spatial Applications in the Housing market, Regional Science and Urban Economics, 58: 78-88

Thanos, S. \& White, M. (2014), Expectation Adjustment in the Housing Market: Insights from the Auction System in Scotland, Housing Studies, 29(3): 339-361.

Vega, S. H. \& Elhorst, J. P., 2015. The SLX Model. Journal of Regional Science 55(3), 339-363.

Wooldridge, J.M. (2001). Econometric Analysis of Cross Section and Panel Data, MIT Press. 